\title{
Experimental Study of Vibrational Acceleration Spread and Comparison Using Three Citrus Canopy Shaker Shaking Tines
}

\author{
Tian-Hu Liu, ${ }^{1}$ Reza Ehsani, ${ }^{2}$ Arash Toudeshki, ${ }^{2}$ Xiang-Jun Zou, ${ }^{1}$ and Hong-Jun Wang ${ }^{1}$ \\ ${ }^{1}$ College of Engineering, South China Agricultural University, 483 Wushan Road, Guangzhou, Guangdong 510642, China \\ ${ }^{2}$ School of Engineering, University of California, Merced, 5200 N. Lake Road, SE2-282, Merced, CA 95343, USA \\ Correspondence should be addressed to Tian-Hu Liu; liuparalake@126.com
}

Received 5 June 2017; Revised 22 August 2017; Accepted 14 September 2017; Published 19 October 2017

Academic Editor: Carlo Trigona

Copyright (c) 2017 Tian-Hu Liu et al. This is an open access article distributed under the Creative Commons Attribution License, which permits unrestricted use, distribution, and reproduction in any medium, provided the original work is properly cited.

\begin{abstract}
The goal of this article is to experimentally study how the vibrational acceleration spreads along the branch shaken by PVC tine, steel tine, and nylon tine for citrus canopy shaking harvesting and to compare the difference. PVC tine and steel tine have potential to be used as shaking rod for citrus canopy shaking harvesting. Nylon tine is a commonly used shaking rod. A tractor-mounted canopy shaker was developed to do the trial. The shaking frequency was set at 2.5 and $5 \mathrm{~Hz}$. Experimental results showed that the vibrational acceleration at the shaking spot is not the highest. Spreading from shaking spot to the stem, it increases evidently. When spreading from stems of the outside subbranch to stems of the nearest inside subbranch, its average decrease percentage is $42 \%$. The overall vibrational acceleration of shaking at $5 \mathrm{~Hz}$ is 1.85 times as high as shaking at $2.5 \mathrm{~Hz}$. The overall vibrational acceleration exerted by straight PVC tine and steel tine is 1.77 and 1.97 times as high as that exerted by straight nylon tine, respectively. It is indicated that replacing nylon tine with steel tine or PVC tine helps remove the fruits inside the canopy. Replacing with steel tine is more effective than with PVC tine.
\end{abstract}

\section{Introduction}

Citrus commonly called orange was cultivated in China by $2500 \mathrm{BC}$ [1]. Although the farming history of citrus is more than 4500 years, its main harvest method still stays on hand picking stage. All the operations of hand harvesting ultimately result in the loss of considerable human energy, time, money, and the deterioration of fruits caused by falling on the ground [2]. During the 2012/13 season, less than 9,000 acres citrus trees were mechanically harvested in Florida (FDOC 2013). It is less than 5\% of the Florida's 576,000 acres $\left(2331 \mathrm{~km}^{2}\right)$ citrus trees. According to statistics, manual harvesting of fruit accounts for 30 to $60 \%$ of the total production costs [3]. In 2009, the harvesting cost of citrus fruit in central Florida accounted for about $42 \%$ of the production cost [4]. In 2012, the cost to hand harvest sweet oranges for processed juice increased from between $\$ 1.90$ a box in December/January (early-season fruit) to more than $\$ 2.20$ a box in May/June (late-season fruit) [5].

The importance of citrus has motivated intensive research on mechanical citrus harvesting. Mechanized harvesting (shakers fruits) significantly reduces the period of harvesting of fruits per tree [6]. The research on mechanical harvesting of citrus was started in 1950s in an attempt to reduce the manual labor [7]. Jutras and Coppock [8] investigated different scenarios to design harvesting aids. The first tree shakers used to harvest Florida citrus were developed in the 1960s [9]. These early machines were codesigned with fruit catch frames and could harvest up to an average of 12 trees per hour [10]. Coppock and Jutras [11] studied different type of harvesting aids to make manual harvesting more efficient. Adrian et al. [12] presented fundamental vibration theory and design criteria for inertia type tree shakers. Whitney $[13,14]$ and Whitney and Patterson [15] studied the air shaker harvesting citrus. The air shaker does not contact the fruits. Therefore, it does not cause any fruit bruising. However, it is very noisy and its strong blow will damage the tree. Lenker [16] developed an auger based harvester. Hedden and Coppock [17] concluded that the foliage shaker had performed better than any other harvester tried in their study. Trunk shakers are faster and easier to operate than limb shakers, but they are not well suited to trees larger than $50 \mathrm{~cm}$ in diameter or for trees 


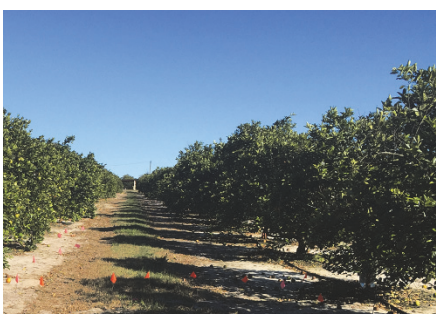

(a)

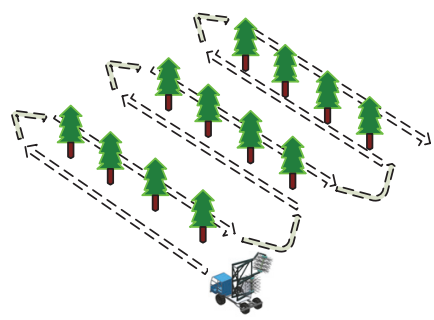

(b)

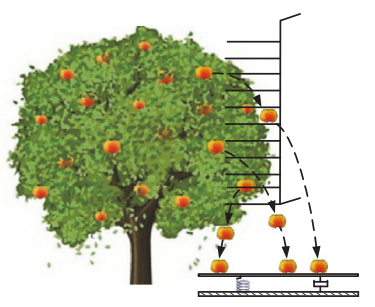

(c)

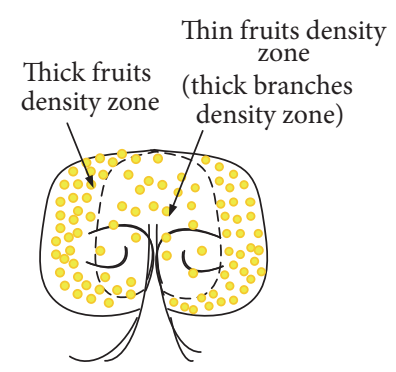

(d)

FIGURE 1: (a) A picture of citrus grove, (b) a schematic drawing of canopy shaking harvester working along the row of citrus groves, (c) a schematic drawing of shaking harvesting, and (d) a schematic drawing of fruits and branch zones.

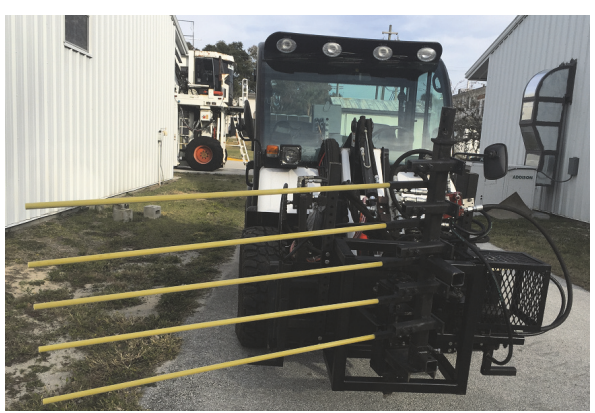

(a)

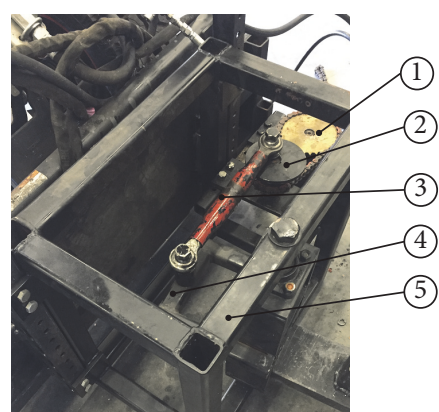

(b)

FIGURE 2: (a) The experimental canopy shaking machine and (b) the vibration mechanism.

with hanging branches [3]. In late 1990s, a prototype similar to the current canopy shaker was designed and developed by Peterson [18]. Savary et al. [19] modeled and simulated the trees using SolidWorks and ANSYS and conducted a field experiment on three Late Navel citrus trees using a tractor-drawn canopy shaker at 180 and 230 cycles per minute (CPM) frequencies. The shaking amplitude and frequency have significant effects $(p<0.01)$ on detaching both ripe and unripe fruits [20]. Sola-Guirado et al. [21] highlighted that the vibration amplitude and the frequency beside the ground speed are the most important factors in efficiently fruit removal. Gupta et al. [22, 23] proposed a progressive analytical approach for the design and optimization of a citrus canopy shaker harvesting machine. Their optimized shaking method reduced $40 \%$ to $45 \%$ of the damage to the limbs of the upper part of the tree canopy.

The overall detachment percentage being low is a main problem concerned about citrus canopy shaking harvesting. Harvesting trial using canopy shaker had indicated the fruit removal efficiency ranges between 80 and 90\%. Analysis of the force and acceleration during the harvest in the tree canopy might give some insightful information for understanding and resolving the raised concerns [24]. Figure 1(a) shows a picture of citrus grove captured in Lake Alfred, Florida, USA. In the process of canopy shaking harvesting, the harvester drives along the row of citrus grove (as shown in Figure 1(b)), the shaker vibrates continuously and the shaking tine inserts into the tree canopy (as shown in Figure 1(c)). The canopy shaking shaker can easily remove the fruits in the outside zone of the canopy. Most fruits bear in that zone [25]. So, it is a thick fruits density zone, as shown in Figure 1(d). But, inside that thick fruits density zone, there is still a thin fruits density zone. Most big branches are also in that zone. Shaking tines inserting into that zone will lead to damage and broken branch. Therefore, in order to shake down fruits in that zone, the vibration must be spread to branches and stems in that zone. It is meaningful to study how the vibrational acceleration spreads along the branch and from outside canopy to the inside. The goal of this article is to experimentally study how the vibrational acceleration spreads along the branch shaken by PVC tine, steel tine, and nylon tine for citrus canopy shaking harvesting and to compare the difference. PVC tine and steel tine have potential to be used as shaking rod for citrus canopy shaking harvesting. Nylon tine is a commonly used shaking rod.

\section{Materials and Methods}

2.1. Testing Equipment. The large canopy shaker is unsuited to do shaking reaction and comparison trials because its adjust ability is very limited. Therefore, an experimental canopy shaking machine was designed and developed for conducting field trials, which is a tractor-mounted canopy shaker with adjustable shaking frequency, tine number, shaking height, and shaking pose and position (as shown in Figure 2(a)). Figure 2(b) shows the detail of the vibration mechanism of the experimental canopy shaking machine, which consisted of five key components, including (1) hydraulic motor 


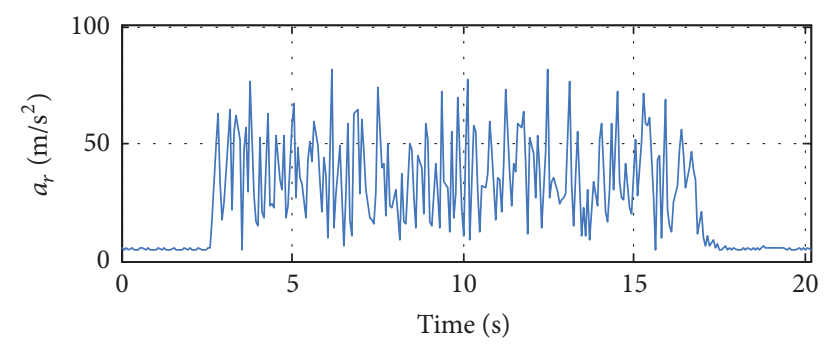

FIGURE 3: The magnitude of acceleration detected by an accelerometer. Because the sensors are set to sense any vibration in three axes up to acceleration of $\pm 6 \mathrm{~g}$, the maximum of the amplitude of acceleration vector can reach as high as $10.3 \mathrm{~g}$.

mounted with a gear, (2) eccentric wheel, (3) telescoping universal joint, (4) rocker, and (5) shaker frame. As the hydraulic motor rotates, it drives the eccentric wheel rotate and further drives the rocker swing through the telescoping universal joint. The pendulum angle of the rocker is about $30^{\circ}$, but it can be adjusted by changing the positon of the connecting hole on the eccentric wheel. The amplitude of the end of the shaking tine is about $300 \mathrm{~mm}$, which is determined by the pendulum angle of the rocker and the distance between the end of the shaking tine and the fulcrum of the rocker. Besides, this experimental canopy shaking machine is a continuous down-the-row operating type.

2.2. Sensor and Data Processing. Four micromachined capacitive accelerometers MMA7260Q (Freescale Semiconductor Inc., 2013) are used as acceleration sensors to detect vibrational acceleration generated by shaking canopy. Its internal sampling frequency is $11 \mathrm{kHz}$. Acceleration occurred in three axes $x, y$, and $z$ and are expressed as $a_{x}, a_{y}$, and $a_{z}$. They are extracted from output voltages $V_{x}, V_{y}$, and $V_{z}$. Those sensors are set to sense any vibration in three axes up to acceleration of $\pm 6 g$, where $g$ is a constant value referring to the acceleration that the Earth absorbs objects on or nearby its surface due to its natural gravity and $g$ is about $9.8 \mathrm{~m} / \mathrm{s}^{2}$ in test area. Acceleration data in 3D Cartesian coordinates are converted to spherical coordinates. A computer program is used to produce the matrix of acceleration in 3D Cartesian coordinates and to convert it from 3D Cartesian coordinates to spherical coordinates. The expression of the magnitude of acceleration vector $a_{r}$ which is calculated using (1) is obtained in terms of its components $a_{x}, a_{y}$, and $a_{z}$ using the Pythagorean Theorem:

$$
\left|a_{r}\right|=\sqrt{a_{x}^{2}+a_{y}^{2}+a_{z}^{2}}
$$

where $\left|a_{r}\right|$ is an absolute value or $\left|a_{r}\right| \geq 0$.

Next, $\left|a_{r}\right|$ in each experiment are collected and recorded in a database. Then, the acceleration peaks are extracted from the database. Because the sensors are set to sense any vibration in three axes up to acceleration of $\pm 6 \mathrm{~g}$, the maximum of the amplitude of acceleration vector can reach as high as $10.3 \mathrm{~g}$. Figure 3 shows a diagram of the amplitude of acceleration vector detected by an accelerometer. It is rather random. So, the median of acceleration peaks, which has more statistical significance than randomly arranged acceleration peaks, is used in vibrational acceleration analysis. Assuming that $n$ acceleration peaks are observed from the accelerometer, those acceleration peaks are expressed as

$$
\left|a_{r}\right|_{1},\left|a_{r}\right|_{2}, \ldots,\left|a_{r}\right|_{n} .
$$

These $n$ acceleration peaks are rearranged in order from small to large, and the number $k$ acceleration peaks $(1 \leq k \leq$ $n)$ is expressed as $\left|a_{r}\right|_{(k)}$. Then

$$
\left|a_{r}\right|_{(1)} \leq\left|a_{r}\right|_{(2)} \leq \cdots \leq\left|a_{r}\right|_{(n)} .
$$

The median of those acceleration peaks, which is expressed as $\operatorname{Med}\left\{\left|a_{r}\right|\right\}$, is calculated using

$$
\begin{aligned}
& \text { Med }\left\{\left|a_{r}\right|\right\} \\
& = \begin{cases}\left|a_{r}\right|_{((n+1) / 2)} & n \text { is an odd number, } \\
\frac{1}{2}\left(\left|a_{r}\right|_{(n / 2)}+\left|a_{r}\right|_{((n+1) / 2)}\right) & n \text { is an even number. }\end{cases}
\end{aligned}
$$

The MATLAB 2016a (The Mathworks, Inc.) is used in data process and calculating the median of those acceleration peaks. Figure 4 shows the simplified block diagram of the accelerometer and signal conditioning system. Sensors are firmly fixed on the branches and stems using rubber bands, as shown in Figure 5.

The average of the median of the resultant acceleration peaks and their standard deviation, which can reflect the overall trend of acceleration more obviously, are referred to in result analysis. They are in turn calculated using equations (5) and (6):

$$
\left.\overline{\operatorname{Med}\left\{\left|a_{r}\right|\right.}\right\}=\frac{1}{n} \sum_{i=1}^{n} \operatorname{Med}\left\{\left|a_{r}\right|\right\}_{i},
$$

where $\operatorname{Med}\left\{\left|a_{r}\right|\right\}_{i}$ represents the median of the resultant acceleration peaks for tree $i$, and $n$ represents the quantity of trees in a group:

$$
s=\sqrt{\frac{\sum_{i=1}^{n}\left(\operatorname{Med}\left\{\left|a_{r}\right|\right\}_{i}-\overline{\operatorname{Med}\left\{\left|a_{r}\right|\right\}}\right)^{2}}{n-1}} .
$$

\section{Materials}

In this paper, straight PVC tine, straight steel tine, and straight nylon tine are studied and compared in the shaking trials. The straight PVC tine and the straight steel tine are cut from round rods. Figure 6 shows two pictures of shaker which have been installed with those two shaking tines. Straight nylon tine is a commonly used shaking tine for citrus canopy shaking harvesting. It is taken as a contrast for straight PVC tine and straight steel tine. Diameter, length, quality, and bending stiffness of those shaking tines are listed in Table 1.

\section{Methods}

All experiments were conducted on Valencia trees in the grove located at Citrus Research and Education Center, 


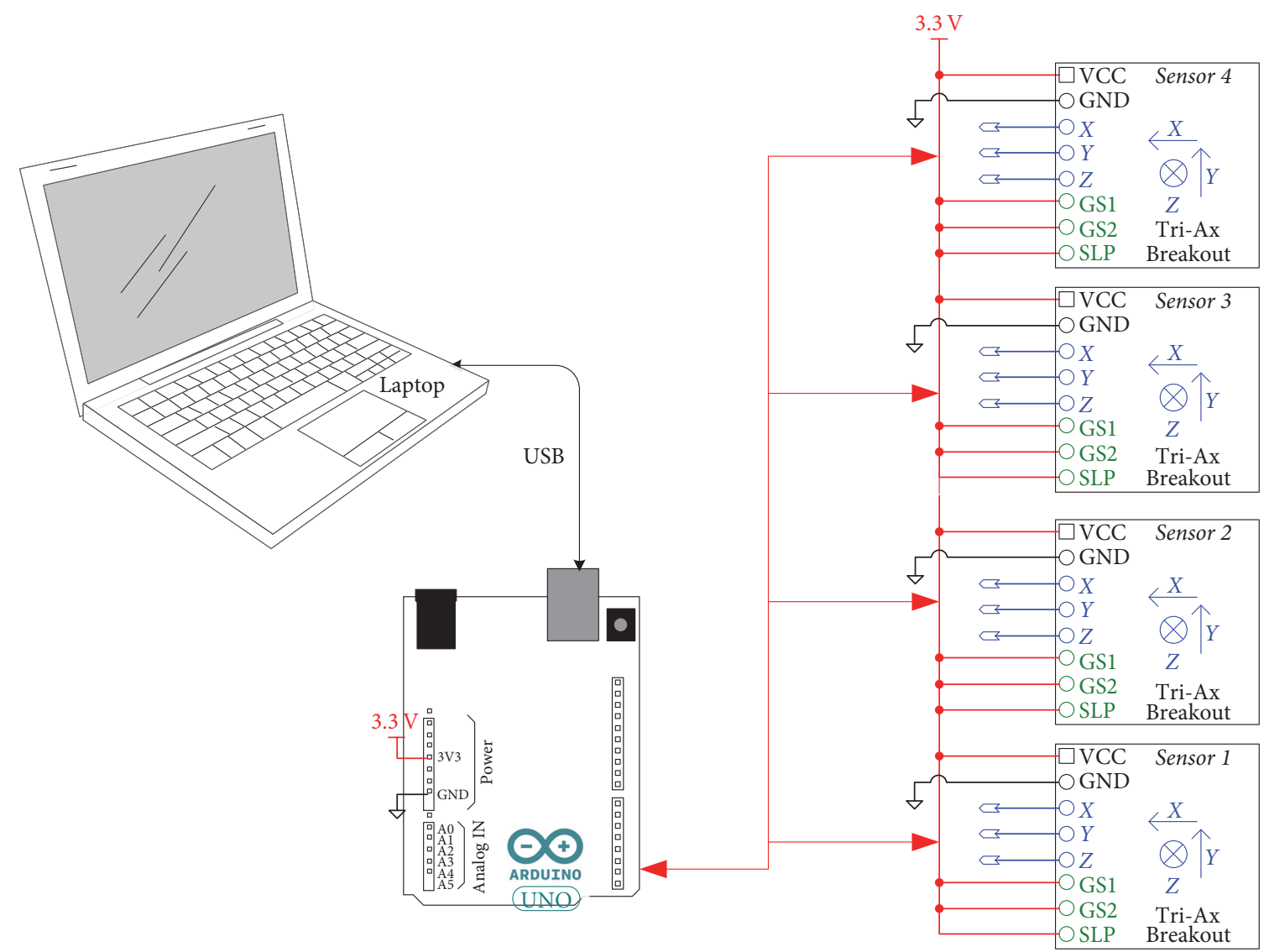

FIgURE 4: The accelerometer and signal conditioning system.

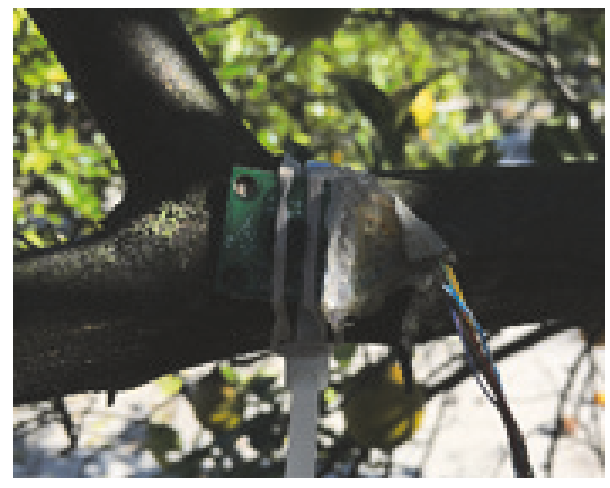

FIGURE 5: Accelerometer fixing methods on branches and stems.

TABLE 1: Physical properties of shaking tines.

\begin{tabular}{lccccc}
\hline $\begin{array}{l}\text { Tine } \\
\text { number }\end{array}$ & Material & $\begin{array}{c}\text { Diameter } \\
(\mathrm{mm})\end{array}$ & $\begin{array}{c}\text { Length } \\
(\mathrm{mm})\end{array}$ & $\begin{array}{c}\text { Quality } \\
(\mathrm{kg})\end{array}$ & $\begin{array}{c}\text { Bending } \\
\text { stiffness }\left(\mathrm{N} \cdot \mathrm{m}^{2}\right)\end{array}$ \\
\hline$(1)$ & PVC & 18.3 & 1220 & 0.74 & 308731 \\
$(2)$ & Steel & 18.3 & 1220 & 2.72 & 769991 \\
$(3)$ & Nylon & 25.4 & 1220 & 0.72 & 19855 \\
\hline
\end{tabular}

Lake Alfred, Florida, USA. Two trials were designed for the research purpose, in which the first one mainly aims at studying how vibrational acceleration spreads along the same branch, and the second one mainly aims at studying how vibrational acceleration spreads in the canopy from outside to inside.

4.1. Vibrational Acceleration Spreads along the Same Branch. 120 trees were selected to do this trial. One typical branch group was selected from each of those 120 trees as a shaking area, which includes a main branch, at least one 1-depth subbranch, at least one 2-depth subbranch and a stem. The shaking frequencies were set at $2.5 \mathrm{~Hz}$ and $5 \mathrm{~Hz}$. The shaking spot is where the shaking tine touches the canopy and pushes the branch moving. In this test, the shaking spot is in the fork between a 2-depth subbranch and a stem. Before every shaking, the free end of the shaking tine stays horizontal and touches the canopy at the shaking spot. The shaking period is $10 \mathrm{~s}$. But if any sensor falls down from the tree before $10 \mathrm{~s}$, the shaking will be stopped. Those 120 trees are averagely divided into 6 groups. The grouping method of those 120 trees are listed in Table 2.

The accelerometer placing method is shown in Figure 7. Sensor 1 is placed in the fork between the main branch and a 1-depth subbranch (location 1). Sensor 2 is placed in the fork between that 1-depth subbranch and a 2-depth subbranch (location 2). Sensor 3 is placed in the fork between that 2depth subbranch and a stem (location 3 ). And sensor 4 is placed at the end of that stem (location 4). 


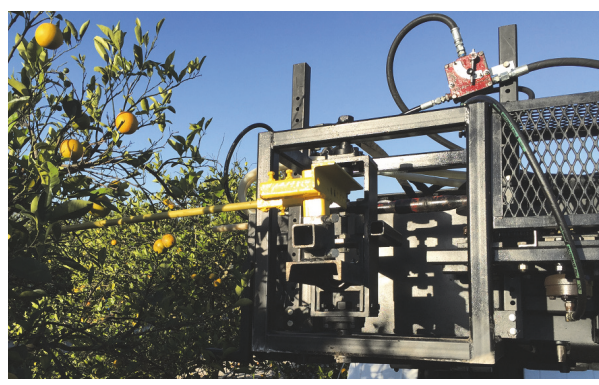

(a)

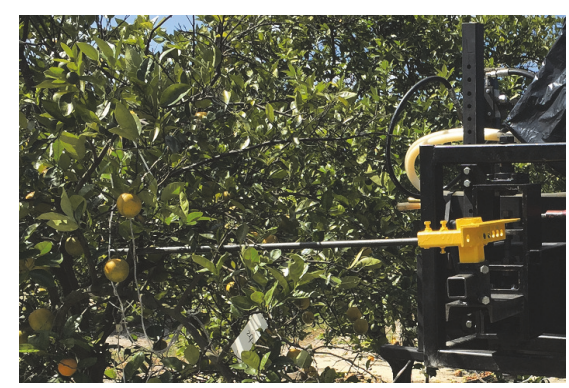

(b)

FIGURE 6: (a) Shaker installed with PVC tine and (b) shaker installed steel tine.

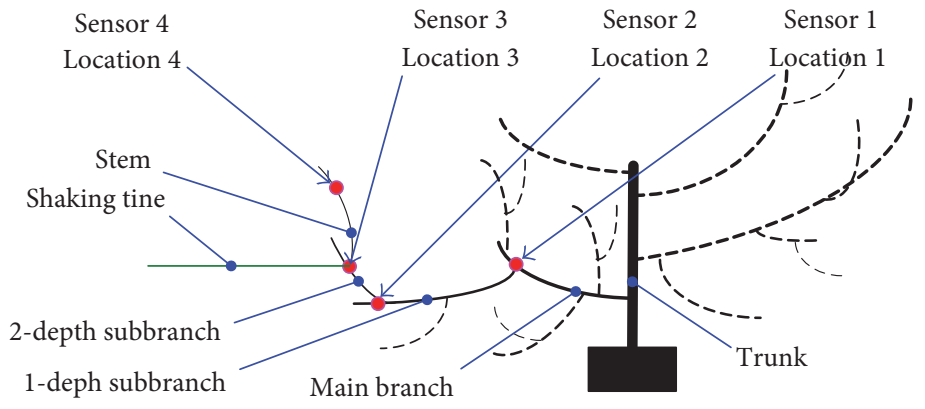

FIGURE 7: The shaking and detecting methods of trial 1.

TABLE 2: The grouping method of experimental trees.

\begin{tabular}{lccc}
\hline $\begin{array}{l}\text { Group } \\
\text { number }\end{array}$ & Tree quantity & Shaking tine & $\begin{array}{c}\text { Shaking } \\
\text { frequency }(\mathrm{Hz})\end{array}$ \\
\hline$(1)$ & 20 & Straight PVC tine & 2.5 \\
$(2)$ & 20 & Straight PVC tine & 5.0 \\
$(3)$ & 20 & Straight steel tine & 2.5 \\
$(4)$ & 20 & Straight steel tine & 5.0 \\
$(5)$ & 20 & Straight nylon tine & 2.5 \\
$(6)$ & 20 & Straight nylon tine & 5.0 \\
\hline
\end{tabular}

4.2. Vibrational Acceleration Spreads in the Canopy from the outside to the inside. The second experiment is designed to observe how the acceleration spreads in the canopy from the outside to the inside. There are also 120 trees used to do this experiment. The structure of branch group selected in this experiment is a little different from the first experiment, in which it includes a main branch and at least two 1-depth subbranches. The first of those two 1-depth subbranches is located at the outside of the canopy. Another one is next to the first one. The experimental tines, shaking frequency, tree grouping method, and shaking period are the same as those of the first experiment. But the shaking spot is located at the fork between an outside 2-depth subbranch and one of its stems.

The accelerometer placing method is shown in Figure 8. Sensor 1 is placed in the fork between the main branch and one inside 1-depth subbranch (location 1). Sensor 2 is placed in the fork between one outside 1-depth subbranch and the

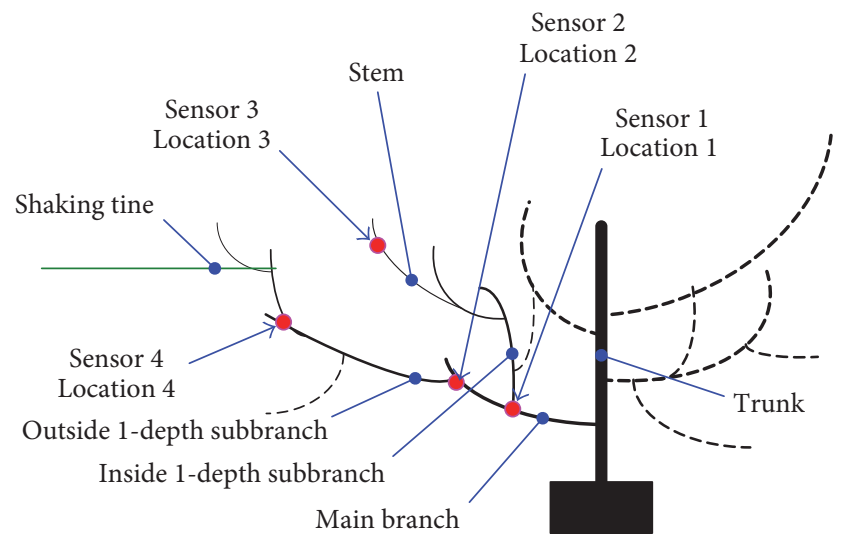

FIGURE 8: The shaking and detecting methods of trial 2.

main branch (location 2). Sensor 3 is placed on a stem of one inside 2-depth subbranch (location 3). Sensor 4 is placed in the fork between that outside 1-depth subbranch and one of its 2-depth subbranches (location 4).

\section{Results and Discussion}

5.1. Vibrational Acceleration Spreads along the Same Branch. The acceleration curves exerted by canopy shaker change dynamically and without any evident regularity, and the maximum of acceleration peaks varies in a large range. This is because, in the process of vibration, the shaking tine and the branch cannot contact together, and their movements 
TABLE 3: The average and standard deviation of the median of the resultant acceleration peaks for trial $1\left(\mathrm{~m} / \mathrm{s}^{2}\right)$.

\begin{tabular}{|c|c|c|c|c|c|c|c|c|c|}
\hline & & \multicolumn{2}{|c|}{ Location 1} & \multicolumn{2}{|c|}{ Location 2} & \multicolumn{2}{|c|}{ Location 3} & \multicolumn{2}{|c|}{ Location 4} \\
\hline & & Average & $\begin{array}{l}\text { Standard } \\
\text { deviation }\end{array}$ & Average & $\begin{array}{l}\text { Standard } \\
\text { deviation }\end{array}$ & Average & $\begin{array}{l}\text { Standard } \\
\text { deviation }\end{array}$ & Average & $\begin{array}{l}\text { Standard } \\
\text { deviation }\end{array}$ \\
\hline \multirow{2}{*}{ PVC tine } & $2.5 \mathrm{~Hz}$ & 5.5 & 2.85 & 9.3 & 3.48 & 16.2 & 11.64 & 29.3 & 17.00 \\
\hline & $5 \mathrm{~Hz}$ & 11.0 & 6.24 & 19.1 & 8.60 & 34.5 & 13.19 & 54.7 & 13.85 \\
\hline \multirow{2}{*}{ Steel tine } & $2.5 \mathrm{~Hz}$ & 7.1 & 2.92 & 11.9 & 6.19 & 21.0 & 6.61 & 37.6 & 10.88 \\
\hline & $5 \mathrm{~Hz}$ & 11.8 & 5.38 & 22.2 & 6.95 & 34.3 & 8.70 & 50.8 & 16.72 \\
\hline \multirow{2}{*}{$\begin{array}{l}\text { Contrast } \\
\text { (nylon tine) }\end{array}$} & $2.5 \mathrm{~Hz}$ & 4.7 & 1.02 & 5.8 & 1.35 & 8.6 & 6.08 & 15.1 & 7.94 \\
\hline & $5 \mathrm{~Hz}$ & 6.1 & 6.40 & 9.7 & 5.73 & 18.3 & 7.95 & 33.6 & 17.03 \\
\hline
\end{tabular}

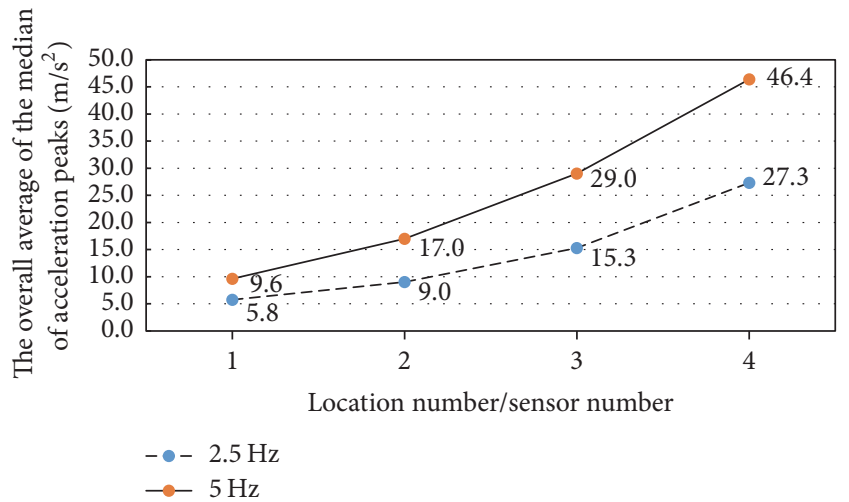

FIGURE 9: The overall average of the median of acceleration peaks for those three shaking tines in trail 1.

are not synchronized. They may impact together anytime. Furthermore, axial rotation of branches and stems may happen anytime, which leads to drastic change in the three axes' acceleration.

Table 3 summarizes the average of the median of the resultant acceleration peaks and their standard deviation. The standard deviation measures the volatility of sample data. The larger the standard deviation is, the greater the volatility of sample data is. The standard deviation values in Table 3 indicate that the volatilities of vibrational acceleration among different trees are very big. The overall average of the median of the resultant acceleration peaks for those three shaking tines is shown as multiline graphs in Figure 9. No matter which shaking frequency and which shaking tine are applied in the shaking, the acceleration at location 1 is the smallest. The acceleration at location 4 is the biggest. And the acceleration at location 3 is bigger than that at location 2 . Such experimental results show that the vibrational acceleration at the shaking spot is not the highest. Spreading from shaking spot to the stem, it increases evidently. Spreading from shaking spot to the trunk, it decreases. This phenomenon can be explained as that the quality of motional material decreases from the branch to the limb. When the vibration energy transfers from the branch to the limb, the vibration amplitude and the vibrational acceleration increase as the quality of motional material decreases. Similarly, the quality of motional material increases from the branch to the trunk,

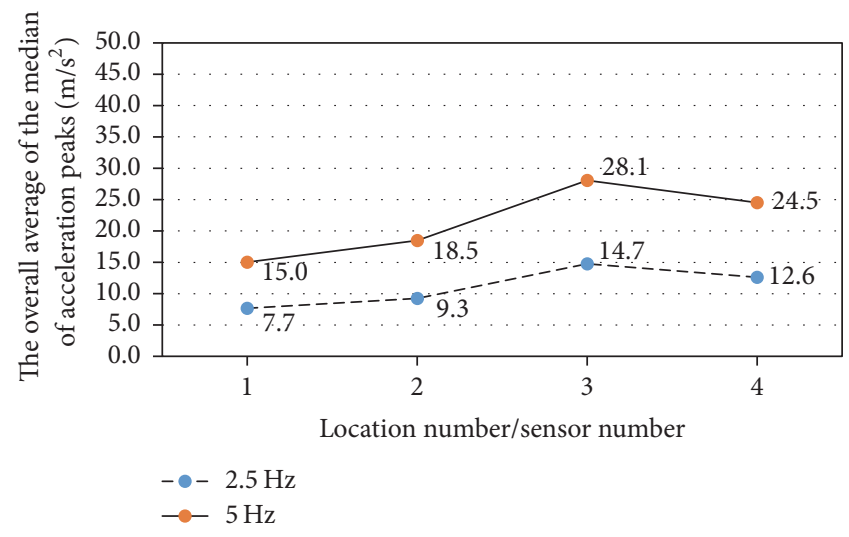

FIGURE 10: The overall average of the median of acceleration peaks for those three shaking tines in trial 2.

so the vibration amplitude and the vibrational acceleration decrease from the branch to the truck. This result agrees with the law of energy transfer in vibration.

5.2. Vibrational Acceleration Spreads in the Canopy from the outside to the inside. Table 4 presents the average of the median of the resultant acceleration peaks and the standard deviation for this trial. The overall average of the median of the resultant acceleration peaks for those three shaking tines is shown as multiline graphs in Figure 10. On average, the acceleration order is location $1<$ location $2<$ location 4 and the location $4<$ location 3 . The results further confirm that, from the shaking spot to the trunk, the acceleration within the same branch decreases.

The resultant acceleration peaks of outside stems are listed in location 4 row of Table 3 . The resultant acceleration peaks of inside stems are listed in location 3 row of Table 4 . It can be found by comparing those two data rows that the acceleration of the outside stems is bigger than that of the inside stems. It is indicated that when the vibrational acceleration spreads from the outside to the inside, it decreases evidently. This is because that as the vibration transfers from the outside of the tree canopy to the inside, only a part of vibration energy will transfer to the inside subbranch and further transfer to its limbs, other will transfer to the trunk. The decrease percentages are listed in Table 5. The overall decrease percentage 
TABLE 4: The average of the median of the resultant acceleration peaks for trial $2\left(\mathrm{~m} / \mathrm{s}^{2}\right)$.

\begin{tabular}{lccccccccc}
\hline & & \multicolumn{2}{c}{ Location 1 } & \multicolumn{2}{c}{ Location 2 } & \multicolumn{2}{c}{ Location 3 } & \multicolumn{2}{c}{ Location 4} \\
Average & $\begin{array}{c}\text { Standard } \\
\text { deviation }\end{array}$ & Average & $\begin{array}{c}\text { Standard } \\
\text { deviation }\end{array}$ & Average & $\begin{array}{c}\text { Standard } \\
\text { deviation }\end{array}$ & Average & $\begin{array}{r}\text { Standard } \\
\text { deviation }\end{array}$ \\
\hline PVC tine & $2.5 \mathrm{~Hz}$ & 8.9 & 9.30 & 10.3 & 3.27 & 16.2 & 6.65 & 13.6 & 4.58 \\
& $5 \mathrm{~Hz}$ & 16.5 & 12.95 & 19.6 & 7.32 & 33.1 & 13.96 & 26.8 & 11.97 \\
Steel tine & $2.5 \mathrm{~Hz}$ & 9.2 & 6.96 & 11.1 & 4.34 & 20.9 & 11.80 & 15.0 & 5.57 \\
& $5 \mathrm{~Hz}$ & 20.3 & 11.75 & 23.2 & 6.31 & 33.7 & 13.62 & 31.4 & 9.82 \\
Contrast & $2.5 \mathrm{~Hz}$ & 4.9 & 2.83 & 6.4 & 2.30 & 7.2 & 3.77 & 9.3 & 2.57 \\
(nylon tine) & $5 \mathrm{~Hz}$ & 8.3 & 11.88 & 12.7 & 3.03 & 17.4 & 6.21 & 15.3 & 6.54 \\
\hline
\end{tabular}

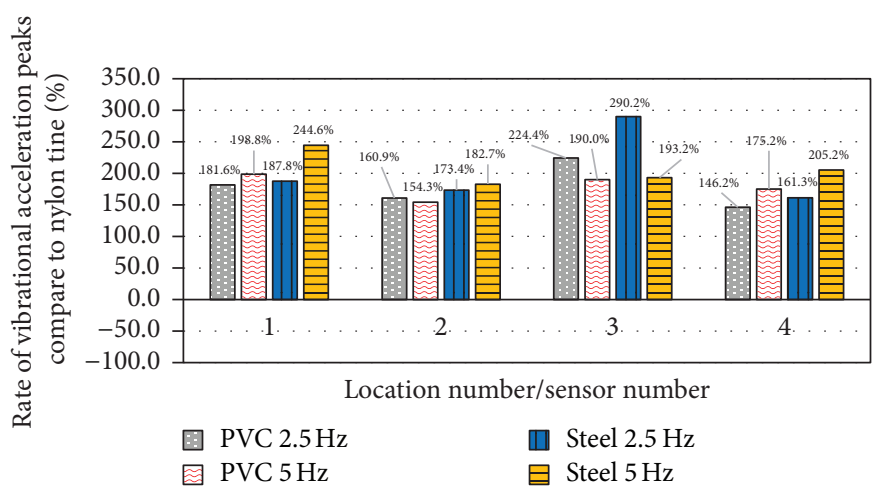

FIGURE 11: The rate of vibrational acceleration peaks exerted by straight PVC tine and straight steel tine compared to straight nylon tine for trial 1.

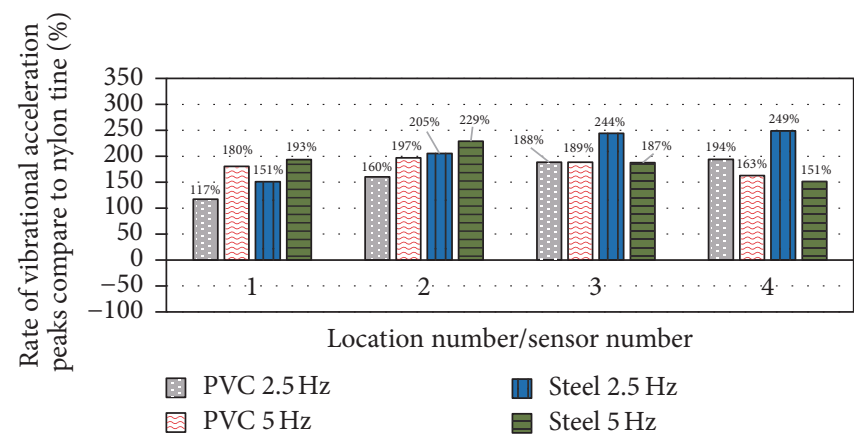

Figure 12: The rate of vibrational acceleration peaks exerted by straight PVC tine and straight steel tine compared to straight nylon tine for trial 2.

of vibrational acceleration spreads from stems of the outside subbranch to stems of the nearest inside subbranch is $42 \%$.

The vibrational acceleration peaks of shaking using straight PVC tine and straight steel tine are much higher than shaking using straight nylon tine. For example, as the vibration frequency is $2.5 \mathrm{~Hz}$, the average of the median of vibrational acceleration peaks shaking using straight steel tine at location 3 is $290.2 \%$ times as much as shaking using straight nylon tine. Figures 11 and 12 show the statistic results of the rate of vibrational acceleration peaks of shaking using straight PVC tine and straight steel tine compared to using nylon tine in histogram. Such results can be explained by bending stiffness difference among those shaking tines. When the bending stiffness increases, the efficiency of the vibration energy of shaking shaker transferring to branches increases. As listed in Table 1, the bending stiffness of straight PVC tine and straight steel tine in turn are 15.5 and 38.8 times as high as straight nylon tine. So, such effects are not a proportional relationship. Synthesizing all those experimental data, the overall vibrational acceleration exerted by straight PVC tine and straight steel tine in turn is 1.77 and 1.97 times as high as that exerted by straight nylon tine. The overall vibrational acceleration of shaking at $5 \mathrm{~Hz}$ is 1.85 times as high as shaking at $2.5 \mathrm{~Hz}$.

The above results and discussions lead to an understanding that replacing nylon tine with steel tine or PVC tine helps remove the fruits inside the canopy. Replacing with steel tine is more effective than with PVC tine. The 
TABLE 5: The average decrease percentage of the median of acceleration peaks.

\begin{tabular}{lcccc}
\hline & & $\begin{array}{c}\text { Outside } \\
\left(\mathrm{m} / \mathrm{s}^{2}\right)\end{array}$ & $\begin{array}{c}\text { Inside } \\
\left(\mathrm{m} / \mathrm{s}^{2}\right)\end{array}$ & $\begin{array}{c}\text { Decrease } \\
\text { percentage }(\%)\end{array}$ \\
\hline PVC tine & $2.5 \mathrm{~Hz}$ & 29.3 & 16.2 & 45 \\
& $5 \mathrm{~Hz}$ & 54.7 & 33.1 & 40 \\
Steel tine & $2.5 \mathrm{~Hz}$ & 37.6 & 20.9 & 44 \\
& $5 \mathrm{~Hz}$ & 50.8 & 33.7 & 34 \\
Contrast & $2.5 \mathrm{~Hz}$ & 15.1 & 7.2 & 52 \\
(nylon tine) & $5 \mathrm{~Hz}$ & 33.6 & 17.4 & 48 \\
\hline
\end{tabular}

second way to increase the removing rate of fruits in the thick branches density zone is to increase shaking frequency. However, we found in other experiments that if the shaking frequency is too high, the stability of the harvesting machine will become worse. According to the theory of mechanical vibrations, if the frequency is the same, acceleration peaks are in proportional to the amplitude. So, under the condition of the shaking frequency staying the same, increasing the shaking amplitude also helps remove the fruits inside the canopy. But the shaking amplitude of most citrus canopy shaker is unchangeable.

\section{Conclusion}

The acceleration curves exerted by canopy shaker change dynamically and without any regularity, and the maximum of acceleration peaks varies in a large range. From the first applied experiment, it was found that the vibrational acceleration at the shaking spot is not the highest. Spreading from shaking spot to the stem, it increases evidently. Spreading from shaking spot to the trunk, it decreases. The second trial indicated that when the vibrational acceleration of shaking spreads from the outside to the inside, it decreases evidently.

The overall vibrational acceleration of shaking at $5 \mathrm{~Hz}$ is 1.85 times as high as shaking at $2.5 \mathrm{~Hz}$. The overall vibrational acceleration exerted by straight PVC tine and straight steel tine in turn is 1.77 and 1.97 times as high as that exerted by straight nylon tine. The overall decrease percentage of vibrational acceleration spread from a stem of the outside subbranch to a stem of the nearest inside subbranch is $42 \%$.

It is indicated that replacing nylon tine with steel tine or PVC tine helps remove the fruits in the thick branches density zone. Replacing with steel tine is more effective than with PVC tine.

\section{Conflicts of Interest}

The authors declare that they have no conflicts of interest.

\section{Acknowledgments}

The authors greatly appreciate the assistance of Mrs. Sherrie M. Buchanon, Mr. Roy Sweeb, and Mr. Joseph Reichling Trotochaud for developing the experimental shaking machine which is used in this work. This research is cosupported by Guangdong Science and Technology Plan Project with Research Grant 2017A010102024, National Key R\&D Plan of China with Research Grant 2017YFD0700100, and National Science Project of China with Research Grant 31571568. The authors also would like to acknowledge the China Scholarship Council for financial support.

\section{References}

[1] E. Nicolosi, Z. N. Deng, A. Gentile, S. La Malfa, G. Continella, and E. Tribulato, "Citrus phylogeny and genetic origin of important species as investigated by molecular markers," Theoretical and Applied Genetics, vol. 100, no. 8, pp. 1155-1166, 2000.

[2] S. V. Pathak, M. V. Chavan, and P. U. Shahare, "Development of pedal operated syzygium cumini tree shaker with catching unit," Scientific Journal Agricultural Engineering, no. 1, pp. 8594, 2015.

[3] M. R. Altisent and J. O. Canavate, Fruits and Vegetables in CIGR Handbook of Agricultural Engineering. Volume III: Plant Production Engineering, American Society of Agricultural Engineers, 1999.

[4] R. P. Muraro, "Summary of 2008-2009 Citrus budget for the central Florida (ridge) production region," 2009, http://www .crec.ifas.ufl.edu/extension/economics/pdf/CF_Budget_Summ_ 2008-2009.pdf.

[5] R. P. Muraro, Estimated Average Picking, Road Siding, and Hauling Charges for Florida citrus, 2011-12 Season, Citrus Research and Education Center, University of Florida, Lake Alfred, Fla, USA, 2012.

[6] D. Zivkovic and M. Veljic, "A contribution to determining the economy sour cherry and plum shaking," Agricultural Engineering, vol. 3, pp. 69-78, 2011.

[7] J. D. Whitney, "A review of citrus harvesting in Florida," Transactions of the Citrus Engineering Conference, Florida Section, ASME, vol. 41, pp. 33-59, 1995.

[8] P. J. Jutras and G. E. Coppock, "Mechanization of citrus fruit picking," Proceedings of the Florida State Horticultural Society, vol. 71, pp. 201-204, 1958.

[9] F. M. Roka, R. J. Ehsani, S. H. Futch, and B. R. Hyman, "Citrus mechanical harvesting systems-trunk shakers," EDIS Journal Series No T-00668, 2014, http://edis.ifas.ufl.edu.

[10] G. E. Coppock and S. L. Hedden, "Design and development of a tree shaker harvest system for citrus fruit," Transactions of the ASAE, vol. 11, no. 3, pp. 339-342, 1968.

[11] G. E. Coppock and P. J. Jutras, "An investigation of the mobile picker's platform approach to partial mechanization of citrus fruit picking," Proceedings of the Florida State Horticultural Society, vol. 73, pp. 258-263, 1960.

[12] P. A. Adrian, R. B. Fridley, and C. Lorenzen, "Forced vibration of a tree limb," Transactions of the ASAE, vol. 8, no. 4, pp. 473-475, 1965.

[13] J. D. Whitney, "Citrus fruit removal with an air harvester concept," Proceedings of the Florida State Horticultural Society, vol. 81, pp. 43-47, 1968.

[14] J. D. Whitney, "Performance of three air shaker patterns in citrus," Transactions of the ASAE, vol. 21, no. 3, pp. 435-437, 441, 1978.

[15] J. D. Whitney and J. M. Patterson, "Development of a citrus removal device using oscillating forced air," Transactions of the ASAE, vol. 15, no. 5, pp. 849-855, 860, 1972. 
[16] D. H. Lenker, "Development of an auger picking head for selectively harvesting fresh market oranges," Transactions of the ASAE, vol. 13, no. 4, pp. 500-504, 1970.

[17] S. L. Hedden and G. E. Coppock, "Comparative harvest trials of Foliage and limb shakers in Valencia orange," Proceedings of the Florida State Horticultural Society, vol. 84, pp. 88-92, 1971.

[18] D. L. Peterson, "Mechanical harvester for process oranges," Applied Engineering in Agriculture, vol. 14, no. 5, pp. 455-458, 1998.

[19] S. K. J. U. Savary, R. Ehsani, J. K. Schueller, and B. P. Rajaraman, "Simulation study of citrus tree canopy motion during harvesting using a canopy shaker," Transactions of the ASABE, vol. 53, no. 5, pp. 1373-1381, 2010.

[20] F. Khorsandi, M. Loghavi, and S. Kamgar, "The effects of shaking Frequency and amplitude on the detachment of Estahban dried fig (Ficus carica cv. Sabz)," Iran Agricultural Research, vol. 31, no. 1, pp. 49-62, 2012.

[21] R. R. Sola-Guirado, F. Jimenez-Jimenez, G. L. Blanco-Roldan, S. Castro-Garcia, F. J. Castillo-Ruiz, and J. A. Gil Ribes, "Vibration parameters assessment to develop a continuous lateral canopy shaker for mechanical harvesting of traditional olive trees," Spanish Journal of Agricultural Research, vol. 14, no. 2, Article ID e0204, 2016.

[22] S. K. Gupta, R. Ehsani, and N.-H. Kim, "Optimization of a citrus canopy shaker harvesting system: properties and modeling of tree limbs," Transactions of the ASABE, vol. 58, no. 4, pp. 971985, 2015.

[23] S. K. Gupta, R. Ehsani, and N. H. Kim, "Optimization of a citrus canopy shaker harvesting system: mechanistic tree damage and fruit detachment models," Transactions of the ASABE, vol. 59, no. 4, pp. 761-776, 2016.

[24] S. K. J. U. Savary, R. Ehsani, M. Salyani, M. A. Hebel, and G. C. Bora, "Study of force distribution in the citrus tree canopy during harvest using a continuous canopy shaker," Computers and Electronics in Agriculture, vol. 76, no. 1, pp. 51-58, 2011.

[25] C. E. Schertz and G. K. Brown, "Determining fruit-bearing zones in citrus," Transactions of the ASAE, vol. 9, no. 3, pp. 366$368,1966$. 


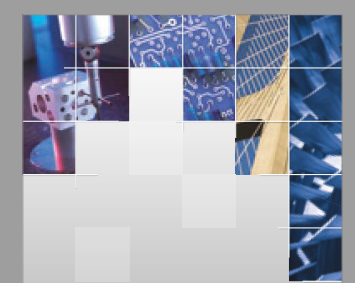

\section{Enfincering}
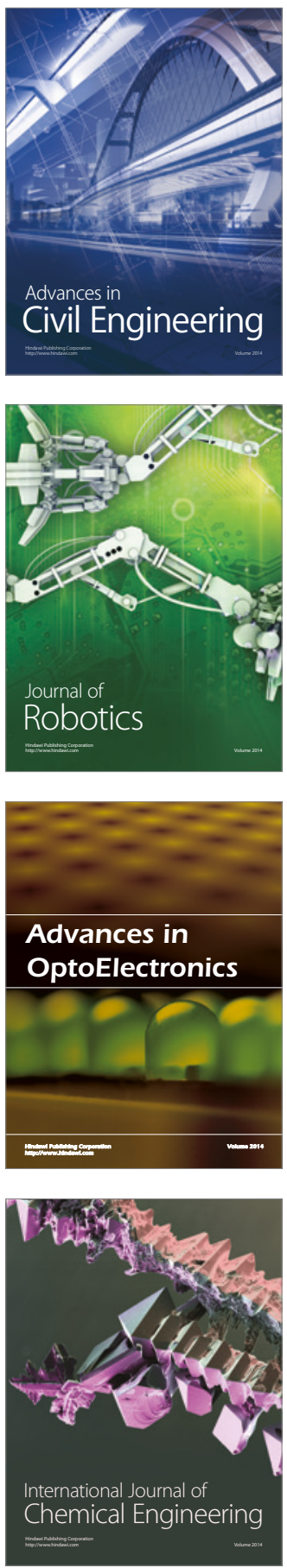

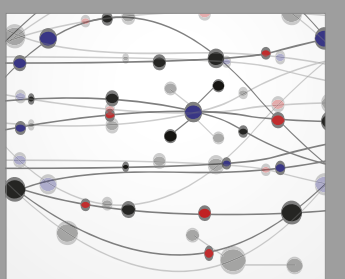

The Scientific World Journal

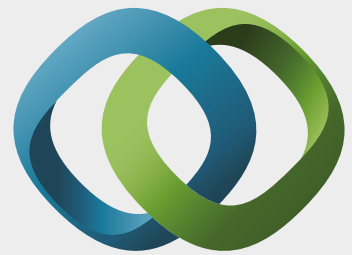

\section{Hindawi}

Submit your manuscripts at

https://www.hindawi.com
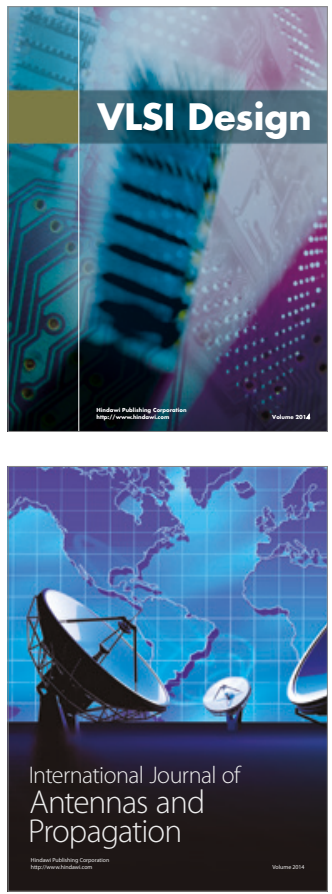

\section{Rotating}

Machinery
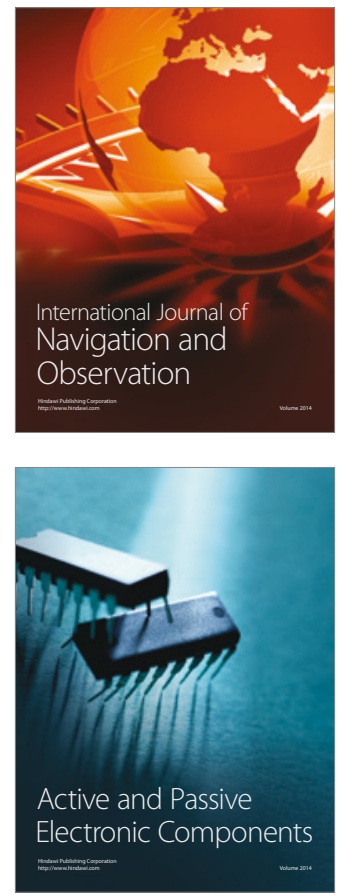
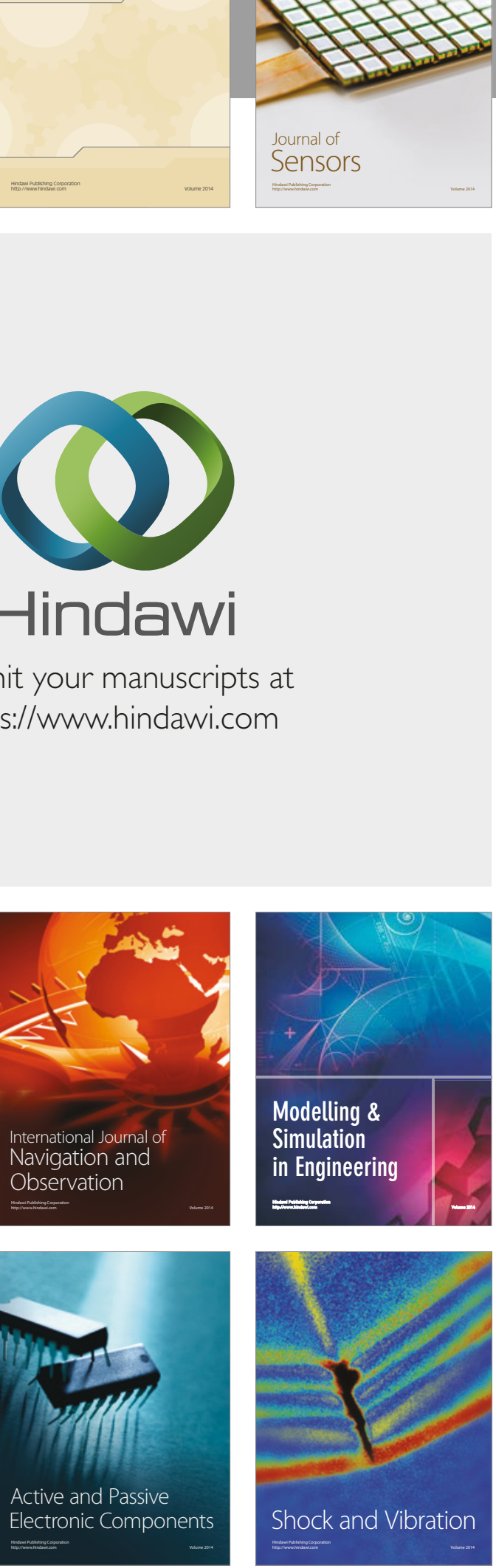
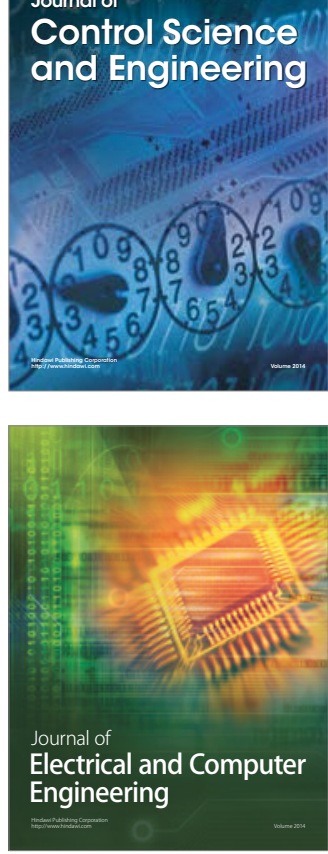

Distributed

Journal of

Control Science

and Engineering
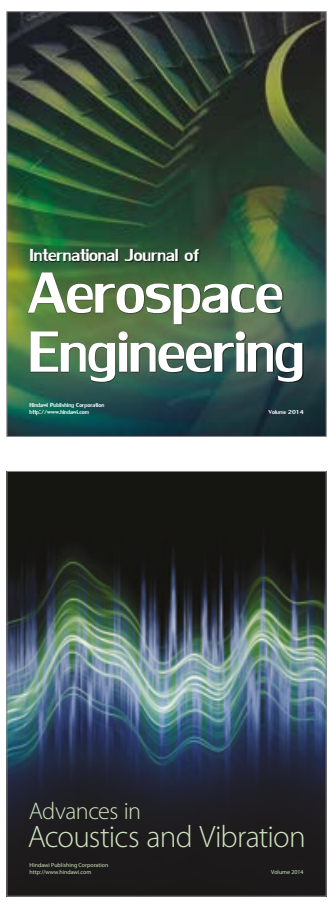

Sensor Networks 